\title{
The Effects Of Bevacizumab Treatment On Thyroid Gland And Pancreas
}

\section{Bevasizumab Tedavisinin Tiroid Bezi Ve Pankreas Üzerine Etkileri}

\author{
Özlem Demircioğlu' ${ }^{1}$, Fatma Buğdaycı Başal ${ }^{2}$ \\ ${ }^{1}$ Marmara Üniversitesi Pendik Eğitim ve Araştırma Hastanesi, Radyoloji Ana Bilim Dalı, İstanbul, Türkiye. \\ ${ }^{2}$ S.B.Ü. Dr. Abdurrahman Yurtaslan Ankara Onkoloji Eğitim ve Araştırma Hastanesi, Medikal Onkoloji Kliniği, \\ Ankara,Türkiye
}

Dergiye Ulaşma Tarihi:19.05.2020 Dergiye Kabul Tarihi:08.07.2020 Doi: 10.5505/aot.2020.56933

\section{ÖZET}

GİRİŞ ve AMAÇ: Bevasizumab, kanser tedavisinde kullanılan ve anjiogenezi inhibe eden bir vasküler endotelyal büyüme faktörü reseptörüdür. Bu etkisinden dolayı bazı deneysel çalışmalarda tiroid ve pankreas boyutlarında azalmaya neden olduğu gösterilmiştir. Bu doğrultuda çalışmada bevasizumab kullanan hastalarda tedavinin tiroid ve pankreas boyutlarının ve fonksiyonları üzerine etkileri araştırılmıştır.

YÖNTEM ve GEREÇLER: Malignite tanısıyla başvuran 50 hastanın evreleme ve takip amacı ile çekilmiş toraks ve abdomen tomografileri retrospektif değerlendirilmiş ve tedavi öncesi ve tedavinin 6 . ayındaki tiroid sağ ve sol lob antero-posterior (AP) çapları ve pankreas baş, gövde ve kuyruk AP çapları ölçülmüştür. Ayrıca hastaların hastane kayıtlarındaki tetkiklerinden kan amilaz, lipaz değerleri ve tiroid fonksiyon testleri aynı zaman dilimlerinde değerlendirilerek karşılaştırılmıştır.

BULGULAR: Yapılan tüm ölçüm değerlerinde bevasizumab tedavisi ile ortalama değerlerde bir miktar azalma gözlenmekle birlikte istatistiksel anlamlı fark saptanmamıştır. Yine yapılan tetkik incelemelerinde sadece 1 hastada tedavinin 6. ayında kan lipaz değerinde yükselme, 3 hastada da tiroid fonksiyon testlerinde bozulma izlenmiş ve anlamlı fark saptanmamıştır.

TARTIŞMA ve SONUÇ: Bevasizumab kullanımı, tiroid ve pankreas boyut ve fonksiyonlarında anlamlı değişiklik yapmamıştır. Fakat anlamlı fark olmasa da yaptığımız ölçümlerde tiroid bezi ve pankreas boyutlarında azalma saptadık. Bu nedenle daha geniş populasyon ve daha fazla hasta sayıları ile yapılacak ayrıntılı prospektif çalışmalara ihtiyaç olduğunu düşünmekteyiz.

Anahtar Kelimeler: Bevasizumab, Tiroid bezi, Pankreas

\section{ABSTRACT}

INTRODUCTION: Bevacizumab is a vascular endothelial growth factor receptor used in cancer treatment that inhibits angiogenesis. Due to this effect, it has been shown in some experimental studies that the thyroid and pancreas sizes are reduced. Accordingly, the effects of Bevacizumab treatment on thyroid and pancreatic dimensions and functions were investigated in this study.

METHODS: Thorax and abdominal tomography taken from 50 patients with malignancy for staging and followup were evaluated retrospectively and thyroid right and left lobe AP diameters and pancreatic head, trunk and tail AP diameters were measured before treatment and at the 6th month of treatment. In addition, blood amylase, lipase values and thyroid function tests were evaluated from patients' tests on the system and compared in the same time frames.

RESULTS: Although a slight decrease in average values was observed with Bevacizumab treatment in all measurement values, there was no statistically significant difference. Again, in the examination studies, only 1 patient showed an increase in blood lipase value and 3 patients have a deterioration in thyroid function tests in the 6th month of treatment and there was no significant difference.

DISCUSSION AND CONCLUSION: It has been observed that bevacizumab use does not significantly change thyroid and pancreatic size and functions. However, even though there is no significant difference, it is thought that detailed prospective studies with more patient groups may be required due to the decrease in the measurements.

Keywords: Bevacizumab, Thyroid gland, Pancreas.

GíRiş onaylanmıştır (1). Bevasizumab, bir kimerik

Bir insan monoklonal antikoru olan bevasizumab, ilk olarak 2004 yılında ileri evre kanserli hastalarda sağkalımı artırmak için vasküler endotelyal büyüme faktörü (VEGF) reseptörü olarak çalışır ve VEGF'i bloke ederek kanser hücrelerinin buraya bağlanmasını önler (2). Böylece tümör hücrelerinin büyümesi için 
gerekli olan endotelyal hücre çoğalmasını ve yeni kan damarı oluşumunu önler. $\mathrm{Bu}$ antitümöral etkinin yanısıra, bevasizumab'ın kanama, bağırsak perforasyonu ve tromboembolik olaylar gibi yaşamı tehdit eden ciddi yan etkilere neden olduğu gösterilmiştir (3). $\mathrm{Bu}$ olumsuz etkilerin yanında bevasizumab'in tiroid yan etkileri hastalarda rapor edilmemiş fakat yapılan hayvan deneylerinde bevasizumab uygulanan ratlarda tiroid ve pankreas volümünde azalma gösterilmiştir (4). Bu doğrultuda çalışmamızda, onkolojik tedavilerinde bevasizumab kullanan hastalarda tiroid bezi ve pankreas boyutlarında değişim olup olmadığı araştırılmıştır. Ayrıca bu hastalarda tiroid fonksiyon testleri ve amilaz, lipaz değerlerindeki değişimler de incelenmiştir.

\section{GEREÇ ve YÖNTEM}

\section{Hasta Seçimi}

Çalışmaya 2017-2019 yılları arasında farklı maligniteler nedeni ile tedavisinde bevasizumab kullanılmış 50 hasta dahil edilmiştir. $\mathrm{Bu}$ hastaların evreleme ve takip amacı ile çekilmiş toraks ve abdomen tomografileri alanında deneyimli tek radyoloji uzmanı tarafindan retrospektif olarak değerlendirildi. Tedavi öncesi ve tedavinin 6 . ayındaki tiroid sağ ve sol lob antero-posterior (AP) çapları ve pankreas baş, gövde ve kuyruk kesiminde AP çapları ölçülmüştür. Tiroid ve pankreas malignitesi veya enflamatuar hastalığı olanlar dışlanmıştır. Ayrıca hastaların hastane kayıtlarındaki mevcut kan amilaz, lipaz değerleri ve tiroid fonksiyon testleri aynı zaman dilimlerinde incelenerek karşılaştırılmıştır.

\section{Görüntüleme}

Toraks ve abdomen tomografileri supin pozisyonunda 64 siralı multi-detektör tarayıcı (GE Medical System, Milwaokee, USA) ile çekim yapılmıştır. Toraks tomografileri tam inspiryumda, akciğer apekslerinden adrenal bezler görüntülene kadar aksiyel planda çekilmiştir. Abdomen tomografileri ise supin pozisyonda, IV ve oral kontrast madde verilerek, diyafram üzerinden iliak kanat üst kenarına kadar olan bölge aksiyal planda çekilmiştir. Görüntüleme parametreleri; kesit kalınlığ $5 \mathrm{~mm}$, kolimasyon $1,25 \mathrm{~mm}$, voltaj 120 $\mathrm{kv}$, akım 120mAs ve FOV $350 \mathrm{~mm}$ olarak ayarlanmıştır.
Olgularin bevasizumab tedavisi öncesinde ve tedavinin 6 . ayında tomografi kesitleri üzerinden pankreas baş, korpus ve kuyruk AP çapları ve tiroid bezi sağ ve sol lobları AP çapları ölçülerek kayıt edildi. Ölçümler yapılırken ilgili uzunlukların en fazla olduğu kesit seçildi.

\section{İstatistiksel Analiz}

Hastaların demografik özellikleri deskriptif analiz ile belirlendi. Tiroid ve pankreas çap değerleri SPSS versiyon 17.0 ile bevasizumab öncesi ve tedavinin 6 . ay1 olacak şekilde iki grup arasında ayrı ayrı bağımsız örneklem t-test ile analiz edildi. $\mathrm{p} \leq 0,05$ değeri istatistiksel olarak anlamlı kabul edildi.

\section{SONUÇLAR}

Hastaların 22'si (\%44) erkek, 28'i (\%56) kadın ve yaş ortalamaları 56 yıl $(25-75$ yıl $)$ idi. Hastaların bevasizumab tedavisinin 6 . ayındaki tiroid sağ ve sol lob ortalama AP çap değerleri, tedavi öncesi değerlere göre bir miktar azalmakla birlikte istatistiksel anlamlı fark saptanmadi. Yine pankreas baş, gövde ve kuyruk AP çap ölçümlerinde iki grup arasında anlamlı fark gözlenmedi. Bu üç değerde de tiroid ölçümlerinde olduğu gibi bevasizumab altında bir miktar azalma izlendi. Ortalama değerler ve $\mathrm{p}$ değerleri tablo l'de verilmiştir.

Cinsiyete göre ölçüm değerlerinin yeniden analiz edilmesinde de benzer şekilde hem kadın hem de erkek cinste, tiroid ve pankreas ölçümlerinde Bevacisumab kullanan grupta küçülme olmakla birlikte anlamlı istatistiksel fark elde edilemedi. Bu ölçümlere ait veriler tablo 2'de verilmiştir.

Tiroid fonksiyon testleri ve pankreas enzimlerinin değerlendirilmesinde gruplar arasinda anlamlı fark saptanmadi. Sadece 1 hastada tedavinin 6. ayında kan lipaz değerinde yükselme gözlendi. 3 hastada da bevasizumab ile tiroid fonksiyon testlerinde bozulma saptandı. Bu 3 hastanın hepsinde TSH değeri yüksekliği, T4 değeri düşüklüğü, 2'sinde de T3 değeri düşüklüğü tespit edildi.

Tablo 1: Bevacizumab öncesi ve 6. ayındaki ortalama değerler ve $\mathrm{p}$ değerleri 


\begin{tabular}{|c|c|c|c|c|c|}
\hline & BEVA & $\mathrm{N}$ & Mean & $\begin{array}{c}\text { Std. } \\
\text { Deviatio } \\
\mathrm{n}\end{array}$ & $\mathrm{p}$ değeri \\
\hline \multirow{2}{*}{$\begin{array}{l}\text { Tiroid } \\
\text { Sağ Lob } \\
\text { AP çap }\end{array}$} & $\begin{array}{l}\text { Beva } \\
\text { öncesi }\end{array}$ & 50 & 24,3000 & 4,39039 & ,978 \\
\hline & $\begin{array}{l}\text { Beva } \\
\text { sonras1 }\end{array}$ & 50 & 22,9200 & 4,41630 & \\
\hline \multirow{2}{*}{$\begin{array}{l}\text { Tiroid } \\
\text { Sol Lob } \\
\text { AP çap }\end{array}$} & $\begin{array}{l}\text { Beva } \\
\text { öncesi }\end{array}$ & 50 & 22,3600 & 5,31367 &, 859 \\
\hline & $\begin{array}{l}\text { Beva } \\
\text { sonras1 }\end{array}$ & 50 & 21,1400 & 5,27996 & \\
\hline \multirow{2}{*}{$\begin{array}{l}\text { Pankreas } \\
\text { Baş } \\
\text { AP çap }\end{array}$} & $\begin{array}{l}\text { Beva } \\
\text { öncesi }\end{array}$ & 50 & 27,1600 & 4,90464 & ,911 \\
\hline & $\begin{array}{l}\text { Beva } \\
\text { sonras1 }\end{array}$ & 50 & 25,6400 & 4,91046 & \\
\hline \multirow{2}{*}{$\begin{array}{l}\text { Pankreas } \\
\text { Gövde } \\
\text { AP çap }\end{array}$} & $\begin{array}{l}\text { Beva } \\
\text { öncesi }\end{array}$ & 50 & 18,6600 & 5,23181 &, 815 \\
\hline & $\begin{array}{l}\text { Beva } \\
\text { sonras1 }\end{array}$ & 50 & 16,9400 & 4,83782 & \\
\hline \multirow{2}{*}{$\begin{array}{l}\text { Pankreas } \\
\text { Kuyruk } \\
\text { AP çap }\end{array}$} & $\begin{array}{l}\text { Beva } \\
\text { öncesi }\end{array}$ & 50 & 14,5200 & 4,06699 & ,849 \\
\hline & $\begin{array}{l}\text { Beva } \\
\text { sonras1 }\end{array}$ & 50 & 13,4400 & 4,20476 & \\
\hline
\end{tabular}

Tablo 2: Cinsiyete göre Bevacizumab öncesi ve 6 . ayındaki ortalama değerler ve $\mathrm{p}$ değerleri.

\begin{tabular}{|c|c|c|c|c|c|}
\hline & BEVA & $\begin{array}{l}\text { Mean } \\
\text { (Kadın) }\end{array}$ & p değeri & $\begin{array}{l}\text { Mean } \\
\text { (Erkek) }\end{array}$ & p değeri \\
\hline $\begin{array}{l}\text { Tiroid } \\
\text { Sağ Lob } \\
\text { AP çap }\end{array}$ & $\begin{array}{l}\text { Beva } \\
\text { öncesi } \\
\text { Beva } \\
\text { sonras1 }\end{array}$ & $\begin{array}{l}23,0357 \\
21,3929\end{array}$ & ,683 & $\begin{array}{l}25,9091 \\
24,8636\end{array}$ & 944, \\
\hline $\begin{array}{l}\text { Tiroid } \\
\text { Sol Lob } \\
\text { AP çap }\end{array}$ & $\begin{array}{l}\text { Beva } \\
\text { öncesi } \\
\text { Beva } \\
\text { sonras1 }\end{array}$ & $\begin{array}{l}21,3929 \\
20,1071\end{array}$ & ,854 & $\begin{array}{l}23,5909 \\
22,4545\end{array}$ & ,958 \\
\hline $\begin{array}{l}\text { Pankreas } \\
\text { Baş } \\
\text { AP çap }\end{array}$ & $\begin{array}{l}\text { Beva } \\
\text { öncesi } \\
\text { Beva } \\
\text { sonras1 }\end{array}$ & $\begin{array}{r}25,8929 \\
23,8929\end{array}$ & ,908 & $\begin{array}{l}28,7727 \\
27,8636\end{array}$ &, 838 \\
\hline $\begin{array}{l}\text { Pankreas } \\
\text { Gövde } \\
\text { AP çap }\end{array}$ & $\begin{array}{l}\text { Beva } \\
\text { öncesi } \\
\text { Beva } \\
\text { sonras1 }\end{array}$ & $\begin{array}{l}18,5000 \\
16,4643\end{array}$ & ,449 & $\begin{array}{c}18,8636 \\
17,5455\end{array}$ &, 453 \\
\hline $\begin{array}{l}\text { Pankreas } \\
\text { Kuyruk } \\
\text { AP çap }\end{array}$ & $\begin{array}{l}\text { Beva } \\
\text { öncesi } \\
\text { Beva } \\
\text { sonras1 }\end{array}$ & $\begin{array}{r}13,7143 \\
12,7143\end{array}$ & ,980 & $\begin{array}{l}15,5455 \\
14,3636\end{array}$ & ,619 \\
\hline
\end{tabular}

\section{TARTIŞMA}

Çalışmamıza dahil hasta grubunda bevasizumab kullanımı sonrasında tiroid bezi ve pankreas boyutlarında anlamlı istatistiksel fark saptanmamıştır. Daha önce yapılan çalışmalarda pankreas, tiroid bezi ve kaslar gibi çeşitli organlarda tirozin kinaz inhibitörleri sorafenib ve sunitimib kullanımı sonrasında volüm ve fonksiyon kayıpları gösterilmiştir (57). Yapılan bu çalışmalarda normal dokularda, ilaç kullanımına bağlı mikro vaskülarizasyon bozulması sonucunda atrofi oluştuğu düşünülmüştür. Mikro vaskülarizasyonun bozulmasında ise VEGF inhibisyonu sorumlu tutulmaktadır. Pankreasta meydana gelen atrofi klinik olarak pankreatik kanalda meydana gelen tıkanıklı sonucu prestenotik segmentin progresif olarak atrofiye gitmesine sebep olmaktadır. Böylece kanal içerisinde oluşan yüksek basınç çevredeki asiner hücrelerin kanlanmasinı bozmakta ve atrofiye sebep olmaktadır (8-10). Çalışmamızda bir VEGF inhibitörü olan bevasizumab'ın da aynı etkileri yapıp yapmadığı araştırılmış ve gerek tiroid gerekse pankreas boyut ölçümlerinde tedavi öncesi ve tedavinin 6 . ay1 arasında istatistiksel anlamlı fark saptanmamıştır.

Ayrıca diyabet ve obesitenin pankreas volümünde azalmaya neden olduğu bilinmektedir $(11,12)$. Diğer taraftan tiroidite ve tedavisinde kullanılan levotiroksine sekonder atrofi sebebiyle tiroid volümlerinde gerileme litaratürde çeşitli çalışmalarda gösterilmiştir $(13,14)$. Bu sebeplerden dolay1 oluşabilecek atrofinin yalancı pozitiflik oluşturmaması için çalışmamızdaki pankreatit geçiren, pankreas kitlesi olan, diyabeti olan, aşırı obez ya da tiroiditi olan ve tiroid hormon terapisi gören hastalar çalışmaya dahil edilmemiştir.

Smith ve ark.'larının 16 rat üzerinde yaptığı çalışmada ratlara intratiroideal ve sistemik bevacsizumab uygulanmış, intratiroidal uygulamada herhangi bir fark saptanamazken sistemik kullanımında tiroid ve pankreas volümlerinde istatistiksel olarak anlamlı bir düşme saptanmıştır (4). Fakat türler arasinda pankreas anatomisinin farklilık gösterdiği ve verilerin insanlara genellenemeyeceği daha önceki çalışmalarda bildirilmiștir $(8,19)$. Biz de çalışmamızda bu verileri destekler nitelikte sonuçlar elde ettik ve bevasizumab kullanımı ile tiroid ve pankreas boyutlarında bir miktar azalma olmasına rağmen anlamlı istatistiksel fark saptayamadık.

Yaptığımız çalıșmada volüm ölçümü değil iki boyutlu ölçüm yaparak değerlendirme 
yapmamız ve çalışmanın retrospektif olması dolayıs1 ile hastaların tedavi öncesi ve sonrasinda glandlardaki kanlanmanın değerlendirilememesi çalışmamızın kısıtlayıcı faktörleridir. İleride hastaların bevacsizumab kullanım öncesi ve sonrasında kanlanmanın doppler ultrasonografi ile değerlendirildiği, glandların volümetrik ölçümlerinin tomografi ile yapılacağ 1 ve elastografi ile glandlardaki fibrozisin değerlendirileceği prospektif bir çalışmanın daha aydınlatıcı olacağı görüşündeyiz.

$\mathrm{Bu}$ kısıtlayıcı faktörlerin dışında, diğer taraftan biz çalışmamızda hastaları rutin kontrolleri sirasinca tiroid fonksiyon testleri ve pankreatik enzim testleri bulunan hastalar arasından seçtik. Yapılan eski çalışmalarda sorafenib kullanımı sirasında kan lipaz değerindeki yükselmeden bahsedilmektedir $(15,16,17)$. Fakat biz çalışmamızda sadece 1 hastada kan lipaz değerinin yükseldiği ve 3 hastada da kan tiroid fonksiyon testlerinde değişiklik olduğunu tespit ettik. Bu değerler ise anlamlı istatistiksel fark oluşturmadı.

Sonuç olarak yaptı̆̆ımız çalışmada bevasizumab kullanımının gerek tiroid gerekse pankreas boyut ve fonksiyonlarında anlamlı değişiklik yapmadığı gözlenmiştir. Fakat anlamlı fark olmasa da yapılan ölçümlerde düşüklük saptanması nedeni ile daha fazla hasta sayıs1 ile yapılacak ayrıntılı prospektif çalışmalara ihtiyaç olduğu düşünülmektedir.

\section{REFERANSLAR}

1. Genentech Inc. Avastin (package insert). San Francisco,CA: Genentech Inc, 2009.

2. Brandes A.A, Bartolotti M, Tosoni A, Poggi R, Franceschi E. Practical Management of Bevacizumab-Related Toxicities in Glioblastoma. Oncologist. 2015 Feb; 20(2): 166-175.

3. Qureshi S, Elliott R.B, Herrington J.D. Concurrent gastrointestinal perforation and pulmonary embolism due to bevacizumab in an adult undergoing treatment for stage IV colon cancer. J Oncol Pharm Pract. 2017 Dec;23(8): 625-628.

4. Smith A, Thimmappa J.D, Vanison C, Shires C.B, Sebelik M. The effect of intrathyroidal versus intraperitoneal bevacizumab on thyroid volume and vasculature flow in a rat model. Gland Surg. 2019 Jun;8(3): 212-217.

5. Makita N, Miyakawa M, Fujita T, Iiri T. Sunitinib induces hypothyroidism with a markedly reduced vascularity. Thyroid. 2010 Mar;20(3): 323-6.

6. Antoun S, Birdsell L, Sawyer MB, Venner P, Escudier B, Baracos VE. Association of skeletal muscle wasting with treatment with sorafenib in patients with advanced renal cell carcinoma: results from a placebo-controlled study. J Clin Oncol 2010;28: 1054-60.

7. van Doorn L, Eskens FA, Visser TJ, van der Lugt A, Mathijssen RH, Peeters RP. Sorafenib induced thyroiditis in two patients with hepatocellular carcinoma. Thyroid 2011;21: 197-202.

8. Hescot S, Vignaux O, Goldwasser F. Pancreatic atrophyea new late toxic effect of sorafenib. N Engl J Med 2013;369: 1475-6.

9. Algul H, Treiber M, Lesina M, Schmid RM. Mechanisms of disease: chronic inflammation and cancer in the pancreasea potential role for pancreatic stellate cells? Nat Clin Pract Gastroenterol Hepatol 2007;4: 454-62.

10. Suda K, Matsumoto Y, Fujii H, Miura K, Nobukawa B. Clinicopathologic differentiation of atrophy of the pancreatic body and tail aplasia. Int J Pancreatol 1998;24: 227-35.

11. Karanjia ND, Widdison AL, Leung F, Alvarez C, Lutrin FJ, Reber HA. Compartment syndrome in experimental chronic obstructive pancreatitis: effect of decompressing the main pancreatic duct. $\mathrm{Br} \mathrm{J}$ Surg 1994;81: 259-64.

12. Saisho Y, Butler AE, Meier JJ, Monchamp T, AllenAuerbach M, Rizza RA, et al. Pancreas volumes in humans from birth to age one hundred taking into account sex, obesity, and presence of type-2 diabetes. Clin Anat 2007;20: 933-42.

13. Migdalis IN, Voudouris G, Kalogeropoulou K, Iliopoulou V, Koutoulidis K, Samartzis M. Size of the pancreas in non-insulin-dependent diabetic patients. J Med 1991;22: 179-86.

14. Svensson J, Ericsson UB, Nilsson $P$, et al. Levothyroxine treatment reduces thyroid size in children and adolescents with chronic autoimmune thyroiditis. J Clin Endocrinol Metab. 2006 May;91(5):1729-34. Epub 2006 Feb 28

15. Romaldini JH, Biancalana MM, Figueiredo DI, et al. Effect of L-Thyroxine Administration on Antithyroid Antibody Levels, Lipid Profile, and Thyroid Volume in Patients with Hashimoto's Thyroiditis. Thyroid. 1996 Jun;6(3):183-8.

16. Escudier B, Eisen T, Stadler WM, Szczylik C, Oudard S, Siebels M, et al. Sorafenib in advanced clear-cell renal-cell carcinoma. N Engl J Med 2007;356: 125-34.

17. Hutson TE, Figlin RA, Kuhn JG, Motzer RJ. Targeted therapies for metastatic renal cell carcinoma: an overview of toxicity and dosing strategies. Oncol 2008;13: 1084-96.

18. Hyodo I, Adachi M, Tsukamoto T, Murai M, Naito S, Akaza H. Serum pancreatic enzyme elevation under treatment with sorafenib. Gan To Kagaku Ryoho 2012;39: 1651-6.

19. Phillip V, Zahel T, Bärtl K, et al. Influence of Sorafenib and Bevacizumab on pancreatic volume A monocentric CT based analysis. Pancreatology. 2016 Jul-Aug;16(4):621-4. 